\title{
RECONSTRUINDO O PASSADO
}

Memórias Migrantes

da Zona Norte de Natal

Julie A. Cavignac*

"Um dia com muito amor pra você eu escrevi

A distância que separa dois corações que se amam

São quilômetros de desejos cada vez mais se apaixonam

$O$ avião ia partindo pela janela eu via ela dando com a mão

Chorando não se conta

A nobre moça que ia no aeroporto deixava

As lágrimas do seu rosto que inutilmente molhava

Desejo, amor, desejo que você possa voltar

Para o nosso matrimônio um dia realizar".

(Milton Lopes de Oliveira, Motorista)

- Conjunto Santa Catarina, Zona Norte/Natal,1996 -

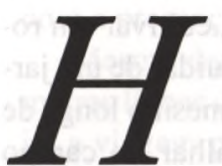

oje, as consequências da passagem rápida do rural ao urbano no Brasil moderno começam a ser apontadas. Fato econômico e histórico determinante na configuração atual do país, esta mutação aparece na realidade bastante complexa e tem consequências sociais e culturais determinantes. Por isso, uma pesquisa sobre as produções narrativas de migrantes morando numa zona periférica da capital do Rio Grande do Norte (a Zona Norte de Natal) ${ }^{1}$, propõe avaliar a transformação de uma cultura dita tradicional (a dos habitantes do interior) num contexto urbano. Isso se torna possível ao avaliar-se a importância das mudanças na composição do corpus narrativo: memorização ou esquecimento das estórias da "tradição", criações poéticas, sumiço dos folhetos de cordel, etc. Da mesma forma, através do relato das suas vidas, é possível perceber as transformações ocorridas na vida cotidiana dos novos moradores da cidade e dos migrantes mais antigos da Zona Norte. Afinal, é a ocasião de propor uma leitura cruzada dos textos orais e escritos da realidade dos migrantes, dos seus discursos e das suas narrativas, sublinhando a importância do corpus narrativo da elaboração de uma identidade e, através desta, mostrar uma apropriação da história do lugar de migração e do espaço.

Mas antes de analisar as narrativas e as histórias de vida, é preciso conhecer o contexto geral das migrações bem como lembrar as linhas gerais da história do local.

\section{A ZONA NORTE}

O Rio Grande do Norte, desde a década de 1970, conhece um êxodo rural importante: em 1991 quase $70 \%$ da população total do Estado era urbana. Durante a última grande seca (1978-1983), Natal e Mossoró tornaram-se pólos atrativos de migração. Além disso, Natal sendo um centro administrativo e devido à sua conjuntura histórica, concentra um grande número de funcionários públicos e de militares. A presença dessa população assalariada relativamente numerosa, ajuda no 
desenvolvimento das atividades ligadas ao comércio, ao turismo e à construção civil. Isso ocorre sobretudo a partir dos anos 1970 e ainda mais depois de 1975 , momento em que o Sudeste do país conhece um unício de recessão e começa a rejeitar os seus imigrantes. Nesse período, em Natal e sobretudo na Zona Norte, foi iniciada a construção de conjuntos habitacionais patrocinados pelos governos estadual e federal.

Situando-se à margem esquerda do rio Potengui, próxima ao município de São Gonçalo de Amarante, a chamada "Zona Norte" conhece, desde os anos 60-70, uma mudança radical. Conjuntos habitacionais (Pajuçara, Igapó, Nova Natal, Panatis, etc.) foram construídos para atender às necessidades de uma população recémurbanizada ou de origem rural, que se integra às camadas de população de baixa renda, mudando profundamente a paisagem do local. O primeiro conjunto construído foi o conjunto Amarante, durante o governo de Mons. Walfredo Gurgel (1964-1970). Nessa época foi desativada a antiga ponte de ferro, que ligava Natal à Zona Norte. Mas, foi nos anos 80 que a Zona Norte passou a ser definitivamente uma zona habitacional. A crise da indústria algodoeira - presente na região - conduziu ao fechamento das principais indústrias têxteis (a Seridó e a Sparta). Esta mudança pode ser percebida através do número crescente dos habitantes: em 1987 viviam aproximadamente 60 mil moradores (Andrade, 1987: 34); em 1997 o número de pessoas se aproxima a $200 \mathrm{mil}$ habitantes e a Zona Norte é considerada como um importante "curral eleitoral".

Atualmente, como nas outras capitais nordestinas, Natal vivencia uma explosão imobiliária, construindo prédios e urbanizando-se cada vez mais. A cidade, então, precisa de um importante contingente de mão-de-obra para trabalhar na construção civil (Morice, 1993: 358)2. Ao mesmo tempo há um grande número de empregos pertencendo ao setor informal (empregadas domésticas ou diaristas sem carteira assinada, artesões e vendedores ambulantes sem registro, independentes, empresas de fundo de quintal, etc.). Geralmente são migrantes que ocupam os empregos menos qualificados: muitos ho- mens trabalham no setor da construção civil ou dos transportes e as mulheres trabalham como empregadas domésticas (Agier, 1995: 82); Clementino, 1995: 317: Morice, 1993). Hoje a Zona Norte é geralmente a melhor opção - do ponto de vista financeiro - para se morar em Natal. Chegando lá, as pessoas não conhecem uma grande mobilidade geográfica; adquirindo o seu imóvel, o migrante passa do estatuto de "estrangeiro" ao de morador de conjunto habitacional ${ }^{3}$.

Porém, esses antigos camponeses não viraram moradores da cidade de uma hora para outra: a Zona Norte possui como característica principal ter ocupado um espaço que antigamente era estritamente rural e que, até hoje, subsiste parcialmente, misturando uma paisagem urbana com resíduos de campo. A proximidade geográfica explica também as intensas relações existentes entre a Zona Norte e as zonas rurais contíguas (São Gonçalo do Amarante, Macaíba, Extremoz) ou com as cidades litorâneas mais próximas, se estendendo às vezes até elas (Redinha e Genipabu). Os moradores dos numerosos conjuntos populares podem ainda exercer atividades agrícolas perto de suas residências - como, por exemplo, cultivar um roçado, plantar uma horta, cuidar de um jardim ou criar animais - ou mesmo longe de suas moradas, indo trabalhar no campo durante a semana ${ }^{4}$.

\section{VIDAS MIGRANTES}

Na verdade é difícil estabelecer uma regra para as migrações; estas são muito variáveis. Porém, é possível afirmar que pelo menos há dois fatores importantes que determinam uma pessoa a migrar: a possibilidade de trabalho e a existência de um parente morando no local.

Podemos pegar a título de exemplo a história de vida de Dona Eva. Ela nasceu em 1948 em Reduto - pequena cidade perto de São Bento do Norte. Seus pais vieram com ela para Natal em 1962, cidade onde já tinham parentes. D. Eva casou e foi para o Rio de Janeiro (1970) acompanhando o esposo e o irmão mais velho. Dois anos depois, veio outra irmã morar com ela. Duas filhas nasceram lá e, em 1977, a família decidiu retornar para o Rio Grande do Norte. Um dos irmãos de Dona
Eva continuou morando no Rio de Janeiro. Ela foi morar na Zona Norte em 1982, participando de projetos educacionais como professora primária. Separou-se do marido (1986) e foi morar com um novo companheiro. Suas filhas, já casadas, continuaram morando perto dela, bem como três irmãos; todos moram em conjuntos habitacionais um pouco distantes um dos outros mas sempre na Zona Norte. Os pais de Dona Eva vivem cada um na casa de um filho: o pai em Parnamirim (município vizinho de Natal) e a mãe em Touros, onde uma parte da família continua morando. Ela mesmo tentou voltar, com o companheiro, para se instalar de vez mas não conseguiu se adaptar e voltou para Natal com uma forte depressão.

Aparece claramente, em todas as etapas da trajetória de Dona Eva, uma preocupação em reagrupar a família: da zona rural (Reduto) para uma cidade do litoral (Touros) e de Touros para a capital do Rio Grande do Norte, desta para o Rio de Janeiro e do Rio de Janeiro novamente para Natal, e afinal para Zona Norte. Neste caso, percebe-se que durante a migração, o grupo não se desagrega; às vezes mesmo a sociabilidade fundada no modelo tradicional da família extensa, se aplica a outros tipos de relacionamentos ${ }^{5}$. $\mathrm{Na}$ realidade, constatam-se uma forte solidariedade e a existência de obrigações recíprocas entre os membros do grupo. Podendo estas se materializarem pela hospedagem de um parente (ou um dos seus amigos) por um período variável e nem sempre especificado. Este elo permite também conceder uma ajuda moral ou afetiva no caso de um evento importante na família (nascimento, doença grave, morte, divórcio, etc.). Pode tratar-se também de uma ajuda material neste caso os parentes próximos (os pais e os irmãos) são solicitados e dificilmente podem negar. Muitas vezes e mesmo com a distância geográfica, as relações continuam intactas entre os que ficam e os que vão embora. Isto é visível nas histórias de vida: no processo de migração existe uma lógica fundada na solidariedade familiar (Cabanes, 1995; Menezes, 1992; Sarti, 1995). Se os principais motivos da migração são econômicos e familiares, no caso das pequenas migrações (intra-estaduais), elas são também motivadas pela procura 
de assistência, no caso de seca, ou de serviço (saúde, educação, administração, etc.).

Outro exemplo nos é dado por Seu Xixi, que nasceu em Estivas (perto de Extremoz) em 1925; cinco anos depois a sua família foi morar em Extremoz. O seu pai morreu quando tinha oito anos e a partir daí começou a trabalhar "na enxada e de barro". Ele não foi para escola - mas sabe ler e escrever - porque teve que sustentar toda a família (eram sete filhos) e tem orgulho de dizer que nenhum deles morreu. Em 1936 ele foi morar emTouros onde trabalhava na prefeitura e onde já morava seu avô (do lado materno). Em 1950, aos 33 anos, chegou na Zona Norte, e casando-se com uma "moça de Igapó", teve nove filhos. Começou trabalhando como servente na prefeitura mas em 1954, foi trabalhar em Belém do Pará numa granja, com um outro irmão. Um ano depois voltou, e começou de novo a trabalhar na prefeitura. Em 1962, Seu Xixi tornou-se sócio do Círculo dos Trabalhadores Cristãos de Igapó e em 1968 foi eleito presidente deste mesmo Círculo que tem como principal objetivo "dar assistência aos seus sócios" . Hoje ele é uma figura de renome na praça de Igapó: homem público, detentor da memória do local, pensou mesmo candidatar-se a vereador.

A trajetória de Seu Xixi, como a de Dona Eva apresentam exemplos de traços característicos de vidas migrantes: eles conheceram uma urbanização progressiva, se deslocando da zona rural para a zona urbana de uma pequena cidade do litoral e fizeram várias pequenas migrações combinadas com uma grande, longe do Nordeste (Sudeste e Amazônia). Esta última, não é considerada uma migração totalmente satisfatória porque eles voltam depois de um tempo longo (sete anos para Dona Eva) ou curto (um ano para Seu Xixi). Quando se estudam as trajetórias dos outros migrantes, novas regularidades aparecem ${ }^{7}$ :

- Numa primeira fase da migração há um problema que obriga a pessoa (ainda jovem) a cuidar do seu destino e/ou a tomar a responsabilidade da família (morte dos pais, separação, problemas financeiros, etc.). Forças maiores são também evocadas - por exemplo, a seca - como sen- do a origem da desgraça e da partida. No caso dos homens, o primeiro emprego é geralmente conseguido com a ajuda dos parentes e se situa no ramo do trabalho informal (Agier, 1995: 97). Como nas narrativas $^{8}$, existe quase sempre uma romantização do tema da partida e do exílio nas histórias de vida e o desejo de "subir na vida" e/ou uma libertação da tutela do pai escondem as razões econômicas da migração.

- Numa segunda fase, há uma construção da própria família com as dificuldades ligadas ao trabalho, à criação dos filhos e à vida longe do local de nascimento. Podem ocorrer várias migrações e há uma grande mobilidade residencial. A dificuldade em se adaptar a uma nova realidade, em poder suportar uma vida tão difícil é compensada pela solidariedade do grupo doméstico. Em vez de se desagregar, a família ganha uma nova força e o sentimento de identificação ao grupo vai ser maior. Nesta fase há uma profissionalização, para os homens e/ou uma centralização do universo da mulher na família.

- Numa terceira fase, a família passa a morar na Zona Norte e/ou volta para o Rio Grande do Norte e em seguida vai morar numa "casa de conjunto", adquirindo o seu próprio imóvel. Geralmente, então, observa-se uma instalação definitiva ou uma estadia prolongada na Zona Norte. A migração, nos relatos dos interlocutores que moraram fora do Estado, é sempre apresentada como temporária - mesmo se, de fato, eles não voltem para morar no seu local de nascimento.

A ligação com o lugar de origem existe e passa pela solidariedade da família, dos vizinhos e dos compadres, mas também pela referência a uma história e a uma cultura comum. Quando são pessoas que não se integraram ao novo contexto urbano e à vida nos conjuntos habitacionais, este lugar é sempre lembrado com saudade. Parece que o sentimento de identificação com o grupo de origem desaparece quando se tratam de filhos dos migrantes ou no caso de migrações satisfatórias. Acontece então uma identificação ao novo local de vida e uma reapropriação do espaço através da rejeição das suas raízes: eles não são mais migrantes, mas sim mo- radores da Zona Norte. Com a negação da identidade passada e a tentativa de apagar a origem, nota-se pouca referência ao corpus narrativo tradicional. Os romances de cordel e as estórias de Trancoso deixam o lugar para outras narrativas e novas poesias, que correspondem melhor ao novo quadro geográfico, social e econômico no qual o indivíduo passa a morar.

É preciso, então, realizar uma pesquisa etnográfica para descobrir o universo de referência dos migrantes, bem como as possíveis estratégias dos candidatos à partida. Ainda assim parece difícil encontrar uma regra para as migrações e os locais de destino. Temos que analisar as histórias de vida detalhadamente para apreendermos a multiplicidade de perfis dos migrantes. A imagem caricatural do pau-de-arara chegando em São Paulo se desmancha em face à multiplicidade dos percursos individuais, levantados durante a pesquisa. Porém, por trás destes variados percursos, podem ser encontradas algumas regularidades temáticas (a família, o trabalho, a moradia) tanto que esses relatos de vida podem ser lidos como "estórias" e tendo uma organização narrativa e temática semelhante. Da mesma forma, vamos examinar agora um mito fundador que nos ajuda a entender como se perpetua um sentimento de identidade no quadro da migração.

\section{O LUGAR DE ORIGEM}

Durante a pesquisa, notamos que várias pessoas entrevistadas voltavam regularmente ao lugar de nascimento numa ocasião como as eleições, as festas religiosas (São João e festas do padroeiro) ou ainda um evento familiar de importância (casamento, batismo, enterro, aniversário, etc.).

Uma pergunta pode ser levantada: qual é o significado das viagens de retorno na construção da identidade dos migrantes (Morice, 1993: 356)? Qual é, ainda, o papel do migrante nas celebrações da cidade? Por exemplo, nas festas de Caicó e de Currais Novos que são dedicadas à Sant'Ana, a padroeira do sertão, se vê um número importante de pessoas "morando fora", quer dizer em Natal ou em outras regiões. Várias semanas antes do começo da festa, os ônibus estão lotados. Alguns fiéis aproveitam a viagem para montar algum tipo de comércio; instalando uma bar- 
raca na praça central ou vendendo artigos de difícil acesso (roupa, bijuteria, perfume, etc.). Isto leva também a refletir sobre a função econômica do migrante que deixou a família para trabalhar na cidade e que contribuiu para sua sobrevivência.

Parece que os migrantes, mais do que outros, estão ligados ao lugar de origem da sua família (pelo menos afetivamente). Mas este lugar, fundador de identidade, parece mais mítico do que real. Não é raro encontrar casos onde várias gerações de um mesmo grupo familiar migraram para outra cidade, Estado ou região. O discurso nostálgico sobre o passado adota às vezes a forma da poesia e nesses momentos também o tempo da infância é sempre lembrado: o período no qual se escutam as estórias e os casos de assombrações, se liam os folhetos de cordel e se ia assistir às cantorias. Além disso o tema da "volta para casa" é muito frequente nas conversas cotidianas, aparecendo também como um tema chave nos romances e nos folhetos de $\operatorname{cordel}^{9}$. Examinando as produções narrativas dos migrantes da Zona Norte, nota-se que as representações do exílio são idênticas no escrito e no oral. Tendo em vista uma leitura conjunta dos textos - romances de cordel, contos, estórias de Trancoso, poesias, etc. - e das histórias de vida, percebe-se claramente que os temas da partida, da saudade, do sofrimento ligado à separação, da vida longe de casa, são tratados de um modo relativamente normativo. Desenha-se então, pouco a pouco, um discurso comum sobre a desgraça e o exílio. Assim é possível avaliar a importância das transformações ocorridas na cultura dos migrantes, bem como na composição do seu corpus narrativo memorização ou esquecimento dos textos "clássicos", criações poéticas, sumiço dos folhetos, etc. - ou mesmo no cotidiano dos novos moradores da cidade ou dos migrantes instalados há mais tempo na Zona Norte.

A referência ao lugar de origem traz ainda com ela várias narrativas de fundação da cidade, que, em geral tem como ponto de partida a história de um santo, um relato de um milagre. Através de um exemplo bastante conhecido, vamos ver como essas narrativas servem de marcadores de identidade, permitindo uma identificação dos migrantes com a história. Assim, várias lendas apresentam viagens de Nossa Senhora: depois de ser descoberta no mato e levada, ela volta ao seu lugar de origem onde é fundada uma capela; núcleo de uma futura cidade ou de um novo santuário. Geralmente dois protagonistas entram em cena: a mãe do Cristo e um colono com um estatuto definido (vaqueiro, caçador ou missionário), morando há vários anos na região. A Virgem aparece sempre como uma figura autóctone porque ela volta sempre de onde vem. Apresenta uma força vital porque consegue levar junto consigo os homens e convertêlos. Ela é viva e o seu deslocamento é impossível, uma vez que está no seu lugar de origem e que a sua aparição sempre se dá num espaço ainda não habitado. Este tipo de história corresponde aos modelos clássicos das aparições de Nossa Senhora e se encontram em outras regiões do mundo. Porém é preciso salientar que a narrativa é sempre integrada à história local e que corresponde ao período de exploração da região. Essa explicação da fundação de um vilarejo ou de uma cidade por um santo pode ser ligada às várias histórias que dão à região sua especificidade. Assim, as circunstâncias e os personagens podem mudar, mas o objetivo é sempre ilustrar o poder da Virgem e do milagre inicial; quer dizer de reforçar a fé dos fiéis.

Esse esquema quase universal da aparição da Virgem e a repetição dos episódios que são marcados por um ritmo ternário mostram que, uma vez que a trama narrativa parece fixada, é transmitida desde as primeiras tentativas de evangelização missionária sem muita modificação. Porém a história é atualizada por uma adaptação dos elementos variáveis (personagens, lugar, data, circunstância, etc.) a um conteúdo local. Parece mesmo possível avançar que essas adaptações locais são o fruto de reinterpretações que reproduzindo a estrutura narrativa, vão descrever as relações que os sertanejos tem com o mundo sobrenatural.

\section{O MILAGRE DA VOLTA}

Temos um exemplo narrativo de uma estátua da Virgem voltando para o seu lugar de origem, através da estória de Nossa Senhora das Vitórias em Carnaúba dos
Dantas contada por Seu Rivaldo. Mesmo tendo migrado há bastante tempo (1953), ele sempre volta lá, onde ainda moram algus membros da sua família (irmãs, tios e primos). Resumindo a narrativa, podemos analisá-la como um mito fundador de um santuário bem como um relato de migração, já que apresenta uma história de retorno para o lugar de nascimento graças à intervenção de Nossa Senhora:

Pedro Alberto, nativo de Carnaúba dos Dantas, vai para Amazônia como seringueiro. Ele fica muito doente (beribéri, cólera, lepra, febre forte, segundo as versões). Num sonho ele vê uma mulher vestida de branco (identificada como uma santa): se ele quiser ficar curado é preciso levar até o Monte do Galo uma es. tátua à sua imagem. Ele fica curado $e$ junta dinheiro para voltar. Pedro Alberto começa a procurar a santa e encontra grandes dificuldades porque não a reconhece. Enfim, ele descobre que se trata de Nossa Senhora das Vitórias. Ele volta para C. dos Dantas pedindo esmola e "idealiza" o santuário do Monte do Galo que era antes famoso por ser um "Reinado Encantado". Até hoje, o Monte do Galo em C. dos Dantas é um dos maiores lugares de romaria do Rio Grande do Norte.

Essa estória insiste sobre a aparição noturna da Virgem, o que irá determinar a volta do exilado. Comparando com os outros relatos de aparição a estrutura narrativa se modifica, mesmo quando a temática geral é respeitada. A Virgem que é muitas vezes associada a uma santa pelos seus nomes diferentes ${ }^{10}$, deseja voltar ao seu "lugar de vida": o Monte do Galo, mesmo que apenas na forma de uma representação material. Essa romaria, que é o preço pago para conseguir uma cura milagrosa é, ao mesmo tempo uma volta simbólica. Normalmente o contrário acontece: o homem pede à santa uma ajuda. Aqui parece que Pedro Dantas leva de volta a santa seridoense perdida na Amazônia. A imagem santa funciona então como um marcador de autoctonia: ela lembra a Pedro Dantas que o Seridó é o seu lugar de nascimento. Pagando a promessa, o protagonista está recompensado (uma cura milagrosa). Ele deverá retribuir com um sacrifício que será feito por meio de uma procura. $\mathrm{O}$ gesto emblemático que consiste em 
trazer uma estátua para um lugar ainda deserto, selvagem e misterioso, é realizado depois, construindo um santuário.

Comparando com outras lendas de fundação, a história do Monte do Galo difere num outro ponto: este lugar sacralizado não determina o nascimento de uma cidade, já que existe um vilarejo a dois quilômetros. Porém, o Monte se tornará um centro de romaria e Pedro Alberto tomará conta do santuário até a sua morte. Essa narrativa que conta a fundação de um lugar santo pode ser lida como um conto maravilhoso já que aqui todas as regras essenciais do esquema narrativo são respeitadas. Descrevendo e explicando uma devoção, essa narrativa gera práticas rituais fundadas no culto aos santos e na retribuição simbólica que necessita da participação efetiva do miraculado nas romarias. Assim, a história fatual é sempre reinterpretada no modo milagroso ou maravilhoso. Enfim, o lugar reservado aos ancestrais - primeiros proprietários fundiários legais ou construtores de santuários - na legitimação da distribuição desigual das riquezas, deixa transparecer uma representação da sociedade que se inspira no modelo da família extensa. Assim em Carnaúba dos Dantas todo mundo acha que pertence a uma família única. É desta maneira que se ilustram as ligações de solidariedade entre os indivíduos sobretudo entre os que têm estatutos desiguais: a família torna-se o modelo ideal pelo qual as relações devem ser realizadas. Mas, se tradicionalmente a filiação e a aliança são geradoras de identidade coletiva, o modelo da família parece também organizar o sagrado. A mãe do Cristo tem um papel determinante na elaboração do sentimento de autoctonia. Essa entidade feminina sobrenatural, associada à figura da mãe, que aparece na natureza e nos sonhos, tem então um papel importante na elaboração e no fortalecimento da identidade do migrante que continua a ter uma ligação forte com sua região de origem $^{11}$.

Seu Rivaldo, mesmo passando a morar na Zona Norte desde $1983^{12}$, não se considera como um verdadeiro morador do Conjunto Nova Igapó, sentindo-se ainda um carnaubense, na tentativa de perpetuar um mito familiar. Ele insiste em dizer que o seu avô, José Alberto Dantas, foi um dos fundadores e o orador oficial na inauguração do cruzeiro comemorativo da fundação de Carnaúba erguido no topo do Monte do Galo no dia 25 de outubro de $1928^{13}$ Além disso, reproduzindo a lenda de fundação, Seu Rivaldo se identifica com os fundadores do Monte e também com a história do lugar. Todo ano, quando volta em outubro para participar das festas de Nossa Senhora das Vitórias, ele pode reviver o sentimento ainda bastante forte, de pertencer à "grande e nobre família unida" de Carnaúba dos Dantas. Além disso, essa referência a um lugar fundador lembra três elementos chaves que tem um papel determinante na definição de uma identidade dos habitantes do interior. A referência a um corpus narrativo comum e bastante estável indica sobre o grau de afinidade com o lugar de nascimento.

No mito fundador do Monte do Galo como nas outras lendas de fundação de cidades - um primeiro elemento de natureza sagrada pode ser destacado: a cidade é fundada por um santo(a) autóctone que foi descoberto(a) no mato - o sagrado é sempre associado à natureza. Um segundo elemento pertencente ao maravilhoso aparece: a existência de mundos antigos, adormecidos e subterrâneos - os "Reinados Encantados". Enfim, um elemento histórico complementa esta representação do passado e do espaço tão singular, podendo ser encontrado na presença dos heróisdesbravadores que vieram povoar uma terra inocupada e trouxeram a civilização. $\mathrm{Na}$ nossa história trata-se de um seringueiro que vê a santa em sonhos, mas podem ser vaqueiros ou colonos que se encontrando numa situação perigosa, chamam o nome da(o) santa(o) para alcançarem os seus pedidos. Se essas narrativas remetem ao lugar de origem, à história do local bem como ao passado da pessoa e sobretudo à infância, e, de fato à elaboração de uma identidade individual, elas se encontram geralmente integradas às histórias de vida dos seus locutores que descrevem a infelicidade na hora da partida, as dificuldades encontradas durante o exílio, a vida familiar, o trabalho, etc. Assim, é preciso examinar a importância do lugar de origem e seu papel na rememoração de uma narrativa fundadora de uma identidade do grupo - formada no modelo da família estendida.

\section{CONSIDERAÇÕES FINAIS}

Uma pesquisa centrada na vida real dos entrevistados privilegia os temas ligados à vida cotidiana dos migrantes bem como ao exílio, à partida da terra natal, e às vezes, a possível volta para o lugar de nascimento. Aponta também para a importância do papel da família e da solidariedade na ocasião da migração, destacando o trabalho como a principal razão do exílio. Permite ainda resgatar um discurso comparativo sobre a vida na região de origem e no lugar de destino, a volta para o Nordeste para os migrantes que se deslocaram para o Sul ou outros Estados fora do Nordeste e, afinal, a instalação e a vida em Natal e na Zona Norte. Enfim, chegando ao nível das narrativas mais tradicionais, que são vivenciadas nos folhetos e nos romances de cordel, como nas estórias de Trancoso, observa-se que estas sofrem um processo de esquecimento e que são geralmente denegridas pelos mais jovens que desconhecem este tipo de literatura, lembrando a sua origem rural. Outras histórias tomam o seu lugar, que, geralmente, seguem uma estrutura narrativa similar. Parece que os tipos de histórias mudam com as identidades dos migrantes.

Assim, a dificuldade que encontramos em colher as narrativas - sobretudo escritas mas também as estórias de Trancoso pode ser explicada pelo fato de que os migrantes, ao chegar na cidade, se esforçam em apagar o estigma do camponês chegando na cidade que é sempre aplicada quando se fala de migrantes. Outras narrativas surgem e, geralmente, o maravilhoso volta com a presença do tema dos mundos subterrâneos que é atualizado com a referência à história recente ${ }^{14}$. Finalmente, algumas correspondências podem ser anotadas entre o processo narrativo e a descrição da realidade, a lógica ficando num nível mais profundo. Assim, na realidade como na ficção narrativa, há uma divisão do universo social entre os homens e as mulheres bem como uma continuidade entre o mundo humano e o sobrenatural. Essa bivalência se reencontra nas formas narrativas onde se torna difícil o estabelecimento da distinção entre a realidade e a ficção ou, o escrito da oralidade. $\mathrm{O}$ mundo sobrenatural - que é uma mistura de elementos cristãos e de figuras perten- 
cendo as bestiário maravilhoso - é omnipresente. Ele se integra numa representação do mundo necessariamente harmônica: os homens entram em contato com os espíritos e os santos para resolverem seus problemas. A presença dos monstros e animais diabólicos na natureza é explicada e aponta para um problema social; no caso da metamorfose de um humano em animal, o pecado (incesto, criança abandonada pela mãe, maldição, etc.) torna-se visível e é punido pela passagem do mundo humano ao reino animal.

Em todos os casos, parece que houve uma acumulação de estórias que foram contadas e recontadas pelos diferentes locutores e poetas. Fora a forma versificada, não existe diferenças fundamentais entre uma estória de Trancoso (oral) e um romance (escrito), ainda menos quando o romance é contado ou decorado. As duas formas adotam uma estrutura narrativa parecida, os personagens são os mesmos, o uso das figuras metafóricas é igual, etc. $\mathrm{Pa}$ rece mesmo que existe uma grande continuidade entre o oral e o escrito. Se a maior parte dos migrantes perdeu seus folhetos de cordel e seus romances, não quer dizer que os esqueceram. Graças à escrita, à leitura e à rememoração das poesias e das estórias, os migrantes defendem e reatualizam os seus valores culturais. Os textos, que lembram um passado mas também um lugar de nascimento, tornam-se veículos de tradição e de identidade. Porém, na zona urbana, pode-se observar o desaparecimento progressivo das expressões da cultura tradicional como os dramas, a cura pelas plantas, os rituais e as procissões e, sobretudo os folhetos de cordel. Para os migrantes, esse desaparecimento vem acompanhado da desagregação das relações sociais que existem nas zonas rurais. A organização espacial das cidades e sobretudo das periferias - conjuntos habitacionais e prédios -, destrói o tipo de sociabilidade tradicional baseada na família numerosa, no conhecimento mútuo e na vizinhança - mesmo se algumas formas de sociabilidade permanecem, como por exemplo a feira semanal. Além disso a identificação dos leitores de cordel com os personagens diminui e explica, em parte, a indiferença dos mais jovens. Os filhos dos migrantes se sentem atraídos por ou- tras formas culturais que são as da cultura urbana. Assim, quando se estuda a história dos folhetos, o seu modo de transmissão ou mesmo a vida dos poetas, constatase que as criações narrativas e poéticas são estrangeiras ao universo urbano e que pertencem a uma cultura de migrantes de primeira geração, oriundos das zonas rurais ou continuando a ter fortes ligações com a comunidade de origem. Longe de ser uma reflexão pessimista sobre o desaparecimento total de uma cultura tradicional é um fenômeno clássico; o êxodo rural e a migração representam mutações tão radicais que justificam esse desaparecimento.

* Julie A. Cavignac é Antropóloga, Prof" adjunta I da UFRN (GRAL CNRS UMR 5595 - Toulouse) França).

\section{NOTAS}

1- Este artigo é uma versão resumida do trabalho apresentado no VIII Encontro de Ciências Sociais NorteNordeste - Fortaleza, 1997, no GT Memória, Narração e História Oral e tem como base a pesquisa Memória de Migrantes: estudo etno-literário de uma comunidade da Zona Norte (Natal), financiada pelo CNPq, (19941996).

2- Esse desenvolvimento pode ser também atribuído ao crescimento geral do Estado; em 1996, o Rio Grande do Norte foi o segundo Estado do Brasil inteiro a ver o seu saldo populacional crescer.

3- É Preciso sublinhar que para os Natalenses a Zona Norte e os habitantes "do outro lado do rio" tem uma reputação péssima, sobretudo no que diz respeito à qualidade de vida: transporte, segurança, serviços, açăo política efetiva, saneamento básico, etc. Os moradores de Igapó são até chamados de "indios" pelo fato de ter sido uma antiga aldeia indigena.

4- Alanin Morice (1993: 356) que estuda os migrantes trabalhando na construção em Santa Rita, cidade vizinha de João Pessoa, também nota a existência da categoria "Trabalhador agrícola-pedreiro".

5- Incluindo os parentes próximos ou mais distantes, a sociabilidade estende-se aos antigos vizinhos, aos amigos ou às pessoas com quem estabeleceu uma ligação qualquer (compadre, patrão, colega, etc.).

6- O primeiro Círculo Operário de trabalhadores Cristãos atendia nas Quintas até a Redinha. Foi fundado pelo Padre Augusto Bretão em 19/10/56. Prestava assistência médica e em odontologia através de estagiários. Sua segunda sede foi na Escola Potiguaçu (Governo de Silvio Pedrosa).

7- Na pesquisa, realizada entre 1994 e 1996, 25 pessoas foram entrevistadas (a grande maioria moradores de conjuntos habitaciconais), na tentativa de se colher o testemunho de vários membros de um grupo familiar junto com a memória dos folhetos de cordel, narrativas orais, apontamentos sobre a história da Zona Norte, etc.

8- Muitos romances de cordel e as estórias de Trancoso apresentam o motivo narrativo do exílio inserido numa aventura romanesca que, geralmente, tem um final feliz. 9- Cf. minha comunicação na mesa redonda "Antropoética nordestina", no Congresso da ABA regional, Recife, maio de 1997.

10- Isto aparece claramente com os casos de Santa Rita (dos Impossiveis) que é chamada de Nossa Senhora dos Impossíveis e da padroeira do Seridó e, dum modo geral, do sertão que é também chamada Nossa Senhora Sant'Ana.

11- Quando se trata da Zona Norte, a identificação parece dificil porque a referência aos santos fundadores não é imediata. No caso de Igapó, novas figuras lendárias vão aparecer: são os primeiros - e até hoje únicos - proprietários legítimos da terra; eles doaram uma parte das terras para a Igreja - hoje a praça - e as pessoas foram se apossando delas.

12-Seu Rivaldo José Dantas nasceu em Carnaúba dos Dantas em 1939, foi para Acari em 1953 (pequena cidade vizinha) para estudar e se mudou para Caicó em 1972 para trabalhar "no batalhão" e dois anos depois foi para Campina Grande. Em 1978, quando ele se aposentou, ele decidiu morar em Natal, onde já tinha alguns membros da sua família (irmão e primos maternos), mas só veio morar na Zona Norte em 1983 (antes tinha morado em Nova Descoberta e no Alecrim).

13-Seu Rivaldo forneceu-nos uma cópia do "Discurso oficial pronunciado pelo Sr. José Alberto Dantas no dia 25 de outubro de 1928": aqui o autor propõe um histórico da cidade e do "clã" Dantas mas não fala da visão de Pedro Alberto Dantas.

14- Estamos realizando uma outra pesquisa intitulada Imagens da colonização: contos maravilhosos, narrativas e memórias da Zona Norte (Natal/RN) ou o nascimento de uma identidade mestiça que tenta apontar para a presença de mundos encantados e a sua ocorrência na memória dos moradores de Igapó. Mais do que simples histórias pouco acreditáveis, informam sobre uma representação local do espaço e do tempo - sobretudo o imaginário ligado à colonização.

\section{BIBLIOGRAFIA}

\section{AGIER, Michel}

(1997) "Mobilidades: algumas formas recentes de diferenciação social". Imagens e Identidades do Trabalho (coll.), São Paulo, Hucitec, ORSTOM: 75112.

ANDRADE, Ilza Araújo Leão

(1987) Mapeamento e análise dos conflitos urbanos em Natal. Natal, (mimeo), (MCs).

CABANES, Robert

(1995) "Hommes et femmes entre culture d'entreprise et culture ouvrière. Un exemple brésilien". In: Salariés et entreprises dans les pays du sud. Contribution à une anthropologie politique (coll.). Paris, Karthala.

CAVIGNAC, Julie

(1997) La littérature de colportage au nord-est du Brésil De l'histoire écrite au récit oral. Paris, ed. du CNRS, coll. Pays Ibériques/Amériques.

CAVIGNAC, Julie

(1997) “Romances d'exil: Littérature de cordel et migrations au Brésil". Autre part, 1: 15-39.

CLEMENTINO, Maria do Livramento

(1995) Economia e Urbanização: O Rio Grande do Norte nos anos 70. Natal, UFRN, CCHLA.

MENEZES, Marilda Aparecida de (org.)

(1992) Histórias de Migrantes. São Paulo, Ed. Loyola/CEM.

MENEZES, Marilda Aparecida de

(1996) "Trabalhadores camponeses migrantes. Histórias de Vida e Identidade". Raizes, ano XV, 12: 147-156.

MORICE, Alain

(1993) “Une légende à revoir: I'ouvrier du bâtiment brésilien dans feu ni lieu". Cahiers des Sciences Humaines, 29 (2-3): 349-371.

SARTI, Cynthia Andersen

(1995) "São os migrantes tradicionais?" TravessiaRevista do Migrante, CEM, ano VIII, $\mathrm{n}^{\circ} 23$, setembro-dezembro, pp. 11-13. 